\author{
Andreas Klocke
}

\title{
Introduction to the special issue: Child poverty in Europe
}

Despite the economic boom during the years 2005-2008, poverty in Europe, and child poverty as well, has not abated. The fluctuations in the poverty rate observed in Europe's heartland in recent years have remained within the long-term statistical range. On average, the child poverty rate in Central Europe oscillates around $15 \%$, while the rates in individual countries range between 10-25\% (see the article of Jonathan Bradshaw and Yekaterina Chzhen in this volume). These enormous regional differences are echoed within the individual countries of Europe. In other words, poverty rates differ by as much as $100 \%$ among the regions within a nation. This reflects considerable inequalities in the social living conditions in European societies while demonstrating the limitation of the informative value of current poverty rate statistics. As we do not currently possess a theory of poverty, we shall have to be content with a conventional way of measuring it: a person who has less than $60 \%$ of the average income (median, new OECD equivalence scale) at his/her disposal is considered to be poor. Besides challenging that exactly $60 \%$ of the median equivalent income represents the valid threshold, we must also establish on what target population we are basing our average. If we choose the nation as our reference, all households in that nation become the basis for our calculations. Nevertheless, there are valid arguments for taking either a supranational norm, such as the European average, or a more local norm such as a district. Either procedure is reasonable, depending on our objectives. In any case, the determined poverty rate varies considerably depending on which average we take as our basis. A socially weak district could, on the basis of the average regional income, exhibit a relatively low poverty rate, while in the national context it could have the highest poverty rate.

Looking further back, the OECD statistics exhibit an overall increase in social inequality in Europe during the last 20 years and, accordingly, an overall increase in the poverty rate (OECD 2008). The increasing inequality in income distribution is primarily attributed to the growing inequality in the distribution of wealth and less due to differences in monthly earnings (OECD 2008). In Europe, it is clearly the upper class households in particular that have improved their income situations over the last two decades. The households in the middle classes and those threatened by poverty were able to defend their relative positions over many years. However, in many countries, increasingly the low-income households are the "losers". As a result of the deliberate extension of the lower income segment, many households (for example, in Germany) have descended into 
the realm of poverty. This process, however, is not proceeding uniformly: within the West European heartland, the inequality in income distribution in Germany, Norway, Italy and Finland has increased; in Great Britain and Greece, it has decreased (OECD 2008). From the socio-political viewpoint, some countries have obviously been more successful than others in meeting the challenges of globalisation, even though globalisation has equally impacted all of the countries mentioned above. The extent of poverty is therefore not an irrevocable fate, but rather the result of (socio-)political convictions and decisions.

The current financial and economic crises are, both in the medium and long term, likely to worsen the situations of those European families already threatened by poverty. This is so because the government debts that are currently accumulating will have to be paid off. Future austerity measures that are already under consideration include cuts in expenditure on public infrastructure, a temporary deferral of welfare benefit adjustments, and calculated inflation. Low-income households and their children are those who will be least able to cope with these measures. It has been documented for many years and is scientifically proven that children are experiencing lasting pain due to economic austerity in their families. In particular, educational and health research have produced clear evidence of a social gradient. According to current research, in bivariate analysis, social inequality or poverty is universally shown to be the decisive factor; in multivariate studies, the connection is far less clear. In any case, many of the emotional disturbances in childhood and youth must be seen as a result of the tensions between the demands of biological development and the circumstances the young generation lives in. As youth represents a period of life in which serious physical and psychological changes take place, the effects of the social circumstances on the well-being of children and youth cannot simply be separated from modes of behaviour that arise from the processing of the tasks required by the individual stages of development.

It can be assumed that external influences (social circumstances) impact the behaviour and internal coping with developmental tasks in young people. That is to say, poverty cannot be seen in isolation, but rather only in the context of other social and psychological criteria. Social resources, as an intermediary factor, represent a strong determining force in the relationship between familial poverty and the mental state and future prospects of children. This connection is receiving increasing attention in the scientific community. We must therefore ask which determinants primarily explain the biographies of the young generation. Recent research on health has revealed that it is not so much objective pressures that determine the severity of stress, rather subjectively perceived resources. Not all of the causal relationships among social inequality (poverty) and the social impacts of poverty have been adequately explained. Only longitudinal studies on childhood and youth can deliver vital information on this subject. Answers to the question of the longterm effects on child development of growing up in impoverished circumstances can only be found in longitudinal studies (see article of Sabine Walper in this volume).

If the social cohesion of European societies is to be maintained, it is essential that the well-documented division of societies (OECD 2008) does not continue to progress. Of course, the opportunities for bringing this to a halt are more limited in times of economic crisis than in 'normal' times. Fortunately, however, policies to reduce poverty are not restricted merely to financial transfers to the needy. Social involvement and fair opportunities for all sections of the population can frequently be accomplished by unconventional 
or pragmatic arrangements on the spot, which do not have to solely rely on financial investment: neighbourhood help, sponsorship for young professionals or civic action are examples of successful ways in which poverty can be alleviated without having to struggle for substantial state support. Nevertheless, it is obvious that many of the tasks for fighting poverty lie within the competency of the state. These responsibilities include the provision of a humane system of basic financial security as well as equal opportunities for the poor to participate in society. In this context, a central issue for European societies is the question of how successful we will be in integrating the youth of immigrant families. As a result of demographic shrinkage, practically all European societies are characterised by an increasing ethnic heterogeneity of social structures. A large percentage of families in Europe have an immigration history, but a valid question here is how far back we should go in order to decide whether or not a family is characterised as having an immigration history. The "non-native" European youth of today were born here and already belong to the third generation. Nevertheless, many of these young people feel alienated in the countries of Europe and often live on the fringes of society; many have suffered experiences of poverty. In European welfare states, policies for children and youth in impoverished conditions are an issue that belongs in the realm of social investment (see article of Thomas Olk and Maksim Hübenthal in this volume). It is not, as was often the case in the past, direct support and alimentation that needy children require, but rather state welfare that includes incentives (investments) for an exit from poverty activated by those affected. The persuasiveness of such an approach essentially depends on whether there are realistic chances of a life beyond poverty for society's youth (for example, whether there are adequate jobs and apprenticeship opportunities). But precisely this has been doubted by observers. Yet it is true that access to education represents a key factor for the success of today's youth. Investment in human resources is therefore a "must" both from the social as well as the individual perspective. It remains debatable, however, to what extent social redistribution measures can be dismantled without causing lasting damage to both the opportunities for youth and the cohesive forces of civil society.

The authors of this special issue approach these issues in a variety of ways. On the basis of a longitudinal data set, Sabine Walper examines the effects of earlier experiences of material deprivation on the well-being of children and youth six years later on. It is shown that episodes of poverty have a significant effect on the current state of health of children and youth. These effects can be observed more clearly in girls than in boys and, astonishingly, are more powerful than either the educational status of parents or the type of family. These findings underscore the enormous significance that has to be accorded to the prevention of poverty. All episodes of poverty have an effect on child and youth development that is more enduring than we might be aware of. These results are consistent with the international research landscape, where socialisation issues are increasingly examined on the basis of longitudinal data. It also becomes clear that adolescence, in particular, requires our increased attention after so much attention has in recent years been principally directed to the (early) childhood phase. In their article, Jonathan Bradshaw and Yekaterina Chzhen first provide a current overview of the spread of child poverty in Europe before undertaking a comparative examination of various political approaches to poverty. More and less successful concepts for dealing with poverty can thus be drawn up. While examining the distribution of poverty in childhood, it is striking that certain 
types of family are especially affected by poverty. In this regard, access to the job market is of greatest significance. The authors also elaborate on interesting differences arising out of comparative analyses: some countries exhibit a low poverty rate but large poverty gaps (distance to the poverty threshold). Other countries have comparatively high poverty rates but small poverty gaps. It remains debatable which of these conditions is more favourable from children's perspective, Thomas Olk and Maksim Hübenthal trace in their article the turn-about in policies dealing with poverty from the supportive welfare state to the social investment state. They do so based on the example of the German welfare state. The authors trace the chronology of events in a detailed and informative manner and ask which measures to combat child poverty have proven to be successful in the context of the social investment state. The authors elaborate on a whole series of shortcomings and contradictions in German social policy and complete their analysis with the conclusion that the social investment state is in urgent need of readopting the traditional redistribution idea of the sustaining welfare state if it is to achieve the goal of combating child poverty.

\section{Reference}

OECD 2008. Growing unequal? Income distribution and poverty in OECD countries. Paris: OECD.

Address of the guest editor/Anschrift des Gastherausgebers:

Prof. Dr. Andreas Klocke

Fachhochschule Frankfurt am Main

University of Applied Sciences

Fachbereich Soziale Arbeit und Gesundheit

Nibelungenplatz 1

D-60318 Frankfurt am Main

E-mail: klocke@fb4.fh-frankfurt.de 